\title{
O suicídio: uma reflexão sobre medidas preventivas
}

\author{
Suicide: a reflection on preventive measures \\ Suicidio: una reflexión sobre medidas preventivas \\ Camila Mazza da SILVA ${ }^{1}$ \\ Victor COLUCCI NETO ${ }^{2}$
}

Membro do GEDTRAB - FDRP/USP, Grupo de Estudos em Direito do Trabalho da Faculdade de Direito de Ribeirão Preto - SP, Universidade de São Paulo FDRP/USP Pós-Graduada e Especializada em Direito Material e Processual do Trabalho pela Faculdade de Direito da Universidade Laudo de Camargo - Universidade de Ribeirão Preto (UNAERP) - SP, Brasil. Pós-Graduada em Direito do Trabalho pela Uniasselvi - SC, Brasil. Graduação em Direito pela Faculdades COC de Ribeirão Preto - SP, Brasil ${ }^{2}$ Mestrando - Programa de Pós-Graduação em Direito e Desenvolvimento da Faculdade de Direito de Ribeirão Preto - SP, Universidade de São Paulo FDRP/USP Pós-Graduação Lato Sensu em Direito Processual Civil pela UNAERP - Universidade de Ribeirão Preto - SP, Brasil Graduação em Direito pela Universidade Paulista -UNIP campus de Ribeirão Preto - SP, Brasil

\section{Resumo}

No presente artigo serão trazidos à baila algumas questões relacionadas ao suicídio, sobretudo com relação aos métodos preventivos. Nesse contexto, será abordado o disposto pela OMS, que reconheceu o suicídio como sendo uma prioridade de saúde pública. Em decorrência, publicou em 2014 o primeiro Relatório Mundial de Suicídio da OMS "Prevenção do suicídio: um imperativo global", cujo objetivo seria aumentar a conscientização sobre a importância da saúde pública para as tentativas de suicídio e suicídio, fazendo da prevenção ao suicídio uma alta prioridade na agenda global em termos de saúde pública. No mais, além do disposto pela OMS, será discorrido a respeito da prevenção ao suicídio sob a perspectiva da importância da família, salientando-se para o uso e influência das tecnologias, a busca pelo sentido da vida e a valorização da autoestima em crianças e adolescentes. Para tanto, será realizada pesquisa bibliográfica em livros, revistas, textos e artigos científicos.

Descritores: Suicídio; Prevenção \& Controle; Saúde Pública.

\section{Abstract}

In this article, some issues related to suicide will be brought up, especially in relation to preventive methods. In this context, the provisions of the WHO, which recognized suicide as a public health priority, will be addressed. As a result, in 2014 it published the first WHO World Suicide Report "Suicide prevention: a global imperative", whose aim would be to raise awareness of the importance of public health for suicide and suicide attempts, making suicide prevention a high priority on the global public health agenda. Furthermore, in addition to the provisions of the $\mathrm{WHO}$, it will be discussed about the prevention of suicide from the perspective of the importance of the family, highlighting the use and influence of technologies, the search for the meaning of life and the valorization of self-esteem in children and teenagers. For this purpose, bibliographic research will be carried out on books, magazines, texts and scientific articles.

Descriptors: Suicide; Prevention \& Control; Public Health.

\section{Resumen}

En este artículo, se mencionarán algunos temas relacionados con el suicidio, especialmente en relación con los métodos preventivos. En este contexto, se abordarán las disposiciones de la OMS, que reconoció el suicidio como una prioridad de salud pública. Como resultado, en 2014 publicó el primer Informe Mundial de Suicidio de la OMS "Prevención del suicidio: un imperativo mundial", cuyo objetivo sería crear conciencia sobre la importancia de la salud pública para el suicidio y los intentos de suicidio, haciendo de la prevención del suicidio alta prioridad en la agenda mundial de salud pública. Además, además de las disposiciones de la OMS, se discutirá sobre la prevención del suicidio desde la perspectiva de la importancia de la familia, destacando el uso y la influencia de las tecnologías, la búsqueda del significado de la vida y la valorización de la autoestima en los niños y adolescentes Para ello, se realizará una investigación bibliográfica sobre libros, revistas, textos y artículos científicos.

Descriptores: Suicidio; Prevención \& Control; Salud Pública.

\section{INTRODUÇÃO}

O termo suicídio apareceu pela primeira vez em textos ingleses com a finalidade de substituir o termo "suicídio em si próprio", expressão que até então era utilizada. A etimologia da expressão vem do latim, "sui" = de si próprio, "caedere"= matar= matar ${ }^{1}$. É o ato deliberado de tirar a própria vida, com desfecho fatal ${ }^{2}$.

Sob uma perspectiva ampla do sentido do termo, a Organização Mundial da Saúde - OMS o caracteriza como sendo um ato de violência voltado à própria pessoa, podendo ser subdividido em dois tipos: comportamento suicida e conduta autolesiva. $\mathrm{O}$ primeiro incluiu ideação suicida, tentativas de suicídio e o suicídio consumado. O segundo, a conduta autolesiva, por seu lado, foi resumida em comportamentos de automutilação, que acontecem em situações mais privadas, muitas vezes não chegando a constar de relatórios de saúde pública, sendo, portanto, subnotificadas. Por isso, há uma necessidade de um olhar cuidadoso para esse segundo grupo, sobretudo pelo profissional que os acolhe, já que uma parcela das pessoas que mantêm condutas autolesivas acabam se matando ${ }^{3}$.
Sob essa ótica da autolesão, pode-se entender que os comportamentos de automutilação presentes em crianças e adolescentes comumente têm origem no vínculo desorganizado que os mesmos fazem com aquelas pessoas que lhes infligem ou infligiram dor e sofrimento e que, a partir da internalização deste tipo de vinculação, infligem dor e sofrimento a elas mesmas, por um mecanismo de dissociação ${ }^{3}$.

Ademais, crianças e adolescentes que carecem de raízes culturais possuem problemas de identidade de maneira significativa o que acarreta falta de um modelo que lhes permita resolver seus próprios conflitos. Em situações de estresse podem recorrer a um comportamento autodestrutivo, como a tentativa de suicídio ou o suicídio, isso porque um comportamento suicida normalmente é precedido de eventos estressantes. Eles desencadeiam sentimentos de abandono e desesperança, que são o gatilho para que o evento venha a ocorrer. Quando o tema é o suicídio, deve-se mirar para um fenômeno existente, que é a imitação. Segundo Durkheim, seria um fator psicológico, cuja importância deve ser considerada ${ }^{4}$.

Menciona que a imitação pode ocorrer entre 
indivíduos que não são unidos por nenhum vínculo social, sendo um fenômeno puramente psicológico, já que um homem pode imitar o outro sem que sejam solidários um do outro ou de um mesmo grupo do qual dependam igualmente, sendo certo que, a proporção imitativa não teria o poder de solidarizálos. Não seria necessário que entre eles houvesse comunhão intelectual ou moral, ou mesmo alguma troca de serviços, nem que falassem a mesma língua. Ou seja, o procedimento que utilizamos para imitar os nossos semelhantes é o mesmo que nos serve para reproduzirmos os ruídos da natureza, as formas das coisas, os movimentos dos seres ${ }^{5}$.

Todavia, referido autor afirma que salvo raríssimas exceções, a imitação não é um fator original do suicídio, pois a mesma somente faz aparecer algo que já existia anteriormente, ou seja, um estado que seria a verdadeira causa geradora do ato e que, provavelmente, acabaria encontrando um meio de produzir seus efeitos, ainda que não houvesse qualquer interferência da imitação ${ }^{5}$. Então, qual seria a verdadeira causa geradora do suicídio? Existiriam meios de prevenção?

\section{REVISÃO DA LITERATURA E DISCUSSÃO}

\section{- Como prevenir}

Quando o tema é a prevenção ao suicídio, os olhares devem voltar-se para o que provoca a dor, acolhendo o que a provoca. Diferentemente do que ocorre na posvenção, para a qual os olhares voltam-se para a dor, pois o ato suicida já foi consumado ${ }^{6 .}$

De acordo com a OMS o suicídio é a segunda causa de morte no mundo entre jovens de 15 a 29 anos. E a pergunta que segue é: o que estamos fazendo de errado? O suicídio sempre aconteceu, mas o que ocorre é que na época atual os números aumentaram consideravelmente, e, por isso, há uma necessidade de prestar-se mais atenção aos jovens, despendendo-lhes mais tempo, um tempo de qualidade, aproximando-se de quem se ama, porque aí sim, medidas preventivas podem ser eficazes no combate ao suicídio ${ }^{6}$.

Além disso, insta destacar para a complexidade que envolve o suicídio e, para tanto, os esforços de prevenção ao suicídio exigem coordenação e colaboração entre diversos setores da sociedade, dentre eles o setor da saúde, a educação, trabalho, agricultura, negócios, justiça, lei, defesa, política e até mesmo a mídia. Esses esforços devem ser abrangentes e integrados entre si, já que em uma questão tão complexa como é o suicídio, nenhuma abordagem isolada por si só pode causar impacto ${ }^{6}$.

A OMS reconhece que o suicídio é uma prioridade de saúde pública. E por isso, publicou em 2014 o primeiro Relatório Mundial de Suicídio da OMS "Prevenção do suicídio: um imperativo global", cujo objetivo seria aumentar a conscientização a despeito da importância da saúde pública para as tentativas de suicídio e suicídio, fazendo da prevenção ao suicídio uma alta prioridade na agenda global em termos de saúde pública ${ }^{7}$.

Outra prioridade de referido Relatório é o incentivo e o apoio aos países, para que sejam desenvolvidas ou fortalecidas estratégias abrangentes de prevenção ao suicídio, com uma abordagem multissetorial de saúde pública. Ademais, destaca-se que já em 2008 o suicídio era tido como uma das condições prioritárias no Programa de Ação da OMS para a Saúde Mental (mhGAP). Tal programa fornece orientação técnica baseada em evidências para aumentar a provisão de serviços e os cuidados em países que apresentam maiores quadros de pessoas com transtornos mentais, neurológicos e de uso de substâncias. Já, no Plano de Ação de Saúde Mental da OMS para 2013-2020, publicado em 2014, os Estados Membros da OMS se comprometeram a trabalhar em direção à meta global e reduzir a taxa de suicídio nos países em $10 \%$ até $2020^{7}$.

O referido plano de ação para a saúde mental 2013-2020 foi adotado pela 66 ${ }^{\mathrm{a}}$ Assembléia Mundial da Saúde. Segundo Chan $^{8}$, o novo Plano de Ação Integral de Saúde Mental 2013-2020 é uma conquista marcante, pois concentra a atenção internacional em um problema que há muito é negligenciado e que está enraizado nos princípios dos direitos humanos. Para que o plano de ação seja concretizado, mudanças de atitudes são necessárias, exigindo uma expansão dos serviços, a fim de promover maior eficiência no uso dos recursos. Os quatro principais objetivos do plano de ação são: a) fortalecer liderança e governança eficazes para a saúde mental; b) fornecer serviços abrangentes, integrados e responsivos de saúde mental e assistência social em contextos comunitários; c) implementar estratégias de promoção e prevenção em saúde mental; e d) fortalecer sistemas de informação, evidências e pesquisas em saúde mental. Cada um dos quatro objetivos é acompanhado por um ou dois objetivos específicos, os quais fornecem a base para a ação coletiva mensurável e a realização pelos Estados Membros em relação às metas globais ${ }^{8}$.

Posto isso, pode-se dizer que os suicídios são evitáveis. E para tanto, existem várias medidas que podem ser tomadas em vários níveis, como no populacional, subpopular e individual com a finalidade de evitar suicídio e tentativas de suicídio. Entre essas medidas, tem-se a redução do acesso aos meios de suicídio (por exemplo, pesticidas, armas de fogo, certos medicamentos); mídia responsável; intervenções escolares; políticas públicas de controle do uso de álcool; identificação precoce, tratamento e atendimento de pessoas com transtornos mentais e de uso de substâncias, dor crônica e sofrimento emocional agudo; treinamento de profissionais de saúde não especializados na avaliação e gestão do comportamento suicida; 
cuidados de acompanhamento para pessoas que tentaram suicídio e prestação de apoio comunitário.

Dentre todas estas medidas acima elencadas, a última merece maior atenção, pois uma tentativa de suicídio é o principal fator de risco para uma futura efetivação desse intento. Por isso, essas tentativas devem ser encaradas com seriedade, como um sinal de alerta a indicar a atuação de fenômenos psicossociais complexos. Dar especial atenção a uma pessoa que tentou se suicidar é uma das principais estratégias para se evitar um futuro suicídio?.

Porém, para que sejam efetivadas tais estratégias, necessária a superação de certas questões, como o estigma e o tabu. O estigma é particularmente em relação aos transtornos mentais e ao suicídio, o que significa que muitas pessoas as quais pensam ou pensaram em tirar a própria vida ou que tentaram suicídio não procuraram ajuda e, portanto, não receberam o auxílio de que necessitavam ${ }^{9}$.

Há uma falta de conscientização no que tange ao suicídio ser um grande problema de saúde pública, não havendo uma abordagem adequada com relação a prevenção do mesmo. Além disso, ainda existe a questão do tabu presente em muitas sociedades, que ainda não discutem o tema abertamente. Até $o$ momento, apenas alguns países incluíram a prevenção do suicídio dentre as suas prioridades de saúde, sendo que apenas 38 países relataram ter uma estratégia nacional de prevenção do suicídio. Desse modo, é de suma importância que se aumente a conscientização da comunidade e que os tabus sejam derrubados para que os países façam progressos em relação à prevenção ${ }^{7}$.

Nesse contexto, é essencial que nesse processo de conscientização as escolas estejam envolvidas e preparadas para enfrentar o tema. ${ }^{7}$ Assim, a prevenção também pode ser feita no ambiente escolar, através de um projeto políticopedagógico de prevenção; por meio de criação de parcerias com outros setores e entidades como universidades e serviços de saúde da região, para que sejam construídos projetos voltados à realidade do território de maneira conjunta; desenvolvimento de ações voltadas a cultura da paz, respeito à diversidade e não discriminação, bem como ações de educação em saúde para toda a comunidade escolar ou acadêmica; criação de espaços de diálogos seguros com os estudantes e profissionais, dando especial destaque à expressão dos sentimentos e a escuta compreensiva; organização de programas psicoeducativos e lúdicos sobre saúde mental e suicídio, pois é importante falar sobre o assunto; atuação de maneira direta e imediata em situações de risco, como preconceito, discriminação e violência ${ }^{1}$. Ressalva-se o papel da escola como espaço de fomento pelo desejo à vida e interesse pelo mundo externo, acolhendo os indivíduos que estão no processo de construção de seu projeto de vida ${ }^{1}$.
No Brasil a questão da prevenção deu os primeiros passos no sentido de lançar um plano nacional de prevenção do suicídio ao montar, em 2005, um grupo de trabalho para este fim, formado por representantes do governo, de entidades da sociedade civil e por universidades. Deste plano surgiram as Diretrizes Brasileiras para um Plano Nacional de Prevenção do Suicídio, lançadas em agosto de 2006, em um evento realizado na Pontifícia Universidade Católica do Rio Grande do Sul, em Porto Alegre ${ }^{1}$.

Em referido plano nacional restaram dispostos alguns objetivos a serem alcançados pelo Brasil, tais como desenvolver estratégias de promoção de qualidade de vida, de educação, de proteção e de recuperação da saúde e de prevenção de danos; desenvolver estratégias de informação, de comunicação e de sensibilização da sociedade de que o suicídio é um problema de saúde pública que pode ser prevenido; organizar linha de cuidados integrais (promoção, prevenção, tratamento e recuperação) em todos os níveis de atenção, garantindo o acesso às diferentes modalidades terapêuticas; identificar a prevalência dos determinantes e condicionantes do suicídio e tentativas, assim como os fatores protetores e o desenvolvimento de ações intersetoriais de responsabilidade pública, sem excluir a responsabilidade de toda a sociedade; fomentar e executar projetos estratégicos fundamentados em estudos de custo-efetividade, eficácia e qualidade, bem como em processos de organização da rede de atenção e intervenções nos casos de tentativas de suicídio; contribuir para o desenvolvimento de métodos de coleta e análise de dados, permitindo a qualificação da gestão, a disseminação das informações e dos conhecimentos; promover intercâmbio entre o Sistema de Informações do SUS e outros sistemas de informações setoriais afins, implementando e aperfeiçoando permanentemente a produção de dados e garantindo a democratização das informações; e promover a educação permanente dos profissionais de saúde das unidades de atenção básica, inclusive do Programa Saúde da Família, dos serviços de saúde mental, das unidades de urgência e emergência, de acordo com os princípios da integralidade e da humanização ${ }^{10}$.

Portanto, esses seriam os objetivos dispostos no Plano Nacional de Prevenção do Suicídio que devem ser implementados no Brasil. Tais objetivos podem ser concretizados? Propõe-se para tanto, que estratégias de promoção de qualidade de vida, de recuperação da saúde e de prevenção de danos sejam promovidas pela sociedade, ocorrendo uma maior reflexão sobre a importância da família, sobre o uso moderado de novas tecnologias, pela busca pelo sentido da vida e a valorização da autoestima, sobretudo em crianças e adolescentes. 


\section{- A importância da família}

Estudiosos de diferentes correntes compartilham a opinião de que a família é de suma importância no enfretamento da problemática envolvendo o suicídio e com relação a automutilação. Salientam que grande parte dos adolescentes que são vítimas de suicídio enfrentam no seio de suas famílias algum problema ou sofreram por necessitar de proteção, ou até mesmo, de algum tipo de apoio psicossocial. A família integra uma rede psicossocial que dá suporte ao indivíduo e pode ser um recurso na prevenção ao suicídio. É a experiência na família que demarca/restringe o sentido da vida ao sujeito ${ }^{10}$.

Na percepção atribuída à Durkheim, quanto maior a intensidade do vínculo de pertencimento a um grupo solidamente constituído, menores seriam as probabilidades de ocorrência de suicídio. Ou seja, os indivíduos solteiros teriam maiores probabilidades de cometerem suicídio em relação aos indivíduos casados, da mesma forma, que pais de família com maiores quantidades de filhos teriam menores possibilidades de cometerem suicídio do que pais sem filhos. Salienta-se, que esta visão foi pioneira, ao indicar o centro do vínculo social como sendo a família, que através das relações ali estabelecidas ofereceria ao indivíduo o sentido do pertencimento, fator atualmente reconhecido como relevante para diminuição do suicídio e também da autolesão ${ }^{5}$.

\section{- A influências das tecnologias}

Quando a questão é o uso de tecnologias, deve-se ter em mente que o uso imoderado das mesmas pode ocasionar prejuízos para a saúde do homem, notadamente porque estão associadas a transtornos, como a alienação mental, amnésia digital, ansiedade, despreparo para frustações, compulsão, depressão, déficit de atenção, demência digital, transtornos urbanos, visão comprometida, sono sem qualidade, obesidade, nomofobia, que consiste na fobia causada pelo incômodo ou angústia que é gerada pela incapacidade de acesso a celulares e computadores de maneira geral, bem como a falta de comunicação que se estabelece através deles, situação que pode acarretar crises de ansiedade e depressão, dentre outros prejuízos ${ }^{11}$.

De certa forma, a nomofobia pode ter relação com a depressão, na medida em que se o indivíduo apresenta sintomas de tristeza, falta de prazer, sensação de desânimo, dificuldade de concentração e isolamento social, pode desenvolver nomofobia, pois isolado em sem contato com as demais pessoas, pode recorrer à internet para que esse quadro seja minimizado, fato que é um agravante da condição de dependência e depressão. Em decorrência desse quadro, o indivíduo pode recorrer ao uso dos recursos tecnológicos para se comunicar de forma prazerosa, com progressiva dependência, acarretamento de isolamento, solidão, baixa autoestima, estresse e, por fim, a depressão ${ }^{11}$.
Entre os adolescentes essa situação é ainda pior, já que a vida nas redes sociais tende a criar no jovem um sentimento de que a vida dos amigos e dos outros, mesmo que fantasiosa, é sempre muito melhor que a sua, o que deixa o adolescente ainda mais triste. Nesse contexto, a disseminação de smartphones, tablets e notebooks conjugada com as redes sociais, mudou de maneira significativa o modo como as crianças e adolescentes veem e interagem com o mundo. Esses jovens enfrentam uma exposição nas redes sociais do que falam e fazem, sendo que seus erros podem ficar marcados e ter consequências ${ }^{11}$.

Por outro lado, existe o cyberbullying, que consiste no uso da internet, em especial das redes sociais, para intimidar e hostilizar uma pessoa, fator que ocasiona diversos problemas relacionados ao suicídio e a automutilação entre os adolescentes. Sem contar que muitas vezes a internet é palco de jovens praticando atos suicidas e automutilação online, para chamar a atenção de algumas pessoas ou até mesmo, como forma de pedir ajuda, sem contar com o fato de que as redes sociais muitas vezes camuflam uma "suposta felicidade" .

Essa busca pela felicidade constantemente está atrelada a aquisição contínua de bens e serviços amplamente divulgada pelas redes sociais e meios publicitários. E é esse o ponto de preocupação, pois altos índices de suicídio decorrem da contradição existente entre o modelo de felicidade que é veiculado pelas redes socias através do consumo exacerbado, em contraposição ao fato de que poucos podem consumir, ou mesmo não podem ter acesso ao que veem, ou poucos se contentam com os produtos que consomem ${ }^{11}$.

Nesse cenário podem-se verificar casos em que prevalece a dependência de objetos de desejo, evitando a mediação a favor de outros objetos, o que faz surgir um comportamento marcado pela impulsividade. $\mathrm{Ou}$, em casos diversos, o indivíduo sente-se desiludido ou até mesmo traído por uma promessa que não foi satisfeita, a de que o consumo atrairia a tão sonhada felicidade. Outro fato que merece atenção é que quando os jovens navegam pela internet buscando conteúdos suicidas, maneiras, métodos ou até mesmo algo a respeito de automutilação, os próprios canais de comunicação possuem um recurso de inteligência artificial que detecta posts nas quais a pessoa demonstra estar precisando de ajuda, caso em que a plataforma os redireciona para página com informações sobre o CVV, tudo como forma de prevenção ${ }^{11}$.

Ainda como maneira preventiva, especialistas tem feito recomendações às famílias no que diz respeito ao uso de tecnologias por crianças e adolescentes, podendo ser incluídas as seguintes medidas: evitar o uso de mídias digitais para crianças menores de 24 meses; evitar deixar crianças sozinhas na frente das TVs; escolher programas que tenham 
qualidade; postergar o uso de tecnologias, quanto mais tarde, melhor; para crianças de 2 a 5 anos, 1 (uma) hora no máximo de televisão seria o ideal; evitar uso de aplicativos acelerados e com conteúdo de violência; evitar usar as mídias como meio de acalmar os filhos, pois isso pode causar dificuldade de auto se acalmar ou regular suas emoções; testar o aplicativo antes de disponibilizar para a criança; e, por fim, manter os quartos, refeições e brincadeiras longe dos dispositivos eletrônicos ${ }^{12}$.

\section{- Questionar-se a despeito do sentido da vida}

Antes de adentrarmos no sentido da vida, cumpre fazer uma breve indicação a respeito da morte, notadamente do ponto de vista individualontológico. A morte é um fato que conduz o indivíduo a dimensões simbólicas e existenciais que ultrapassam questões de tempo e espaço. É um acontecimento irremediável que marca o fim da vida humana, e que, portanto, levanta indagações a despeito de qual seria o sentido de viver, requerendo tentativas de respostas. Tais questionamentos são objeto de investigações humanas há tempos, em diferentes culturas e épocas, produzindo formas culturalmente novas capazes de enfrentar os desafios da sobrevivência humana, como o desenvolvimento da ciência, da arte, literatura e religião ${ }^{11}$.

No âmbito da psicologia a pergunta que se faz a respeito da existência humana está no centro do problema da motivação. Sem que se tenha uma hipótese sobre o motivo pelo qual se vive ou se realiza algo, o vazio e a angústia existenciais afetam o homem, abrindo brechas para que transtornos e problemas psíquicos apareçam ${ }^{11}$. Assim, a necessidade e o sentido da vida seriam o impulso de que o homem necessita, enraizado nas camadas mais profundas do psiquismo.

$\mathrm{Na}$ atualidade permanece a busca pela resposta ao "por que vale a pena viver". A resposta pelo qual se vive conduz às instabilidades constantes, decorrentes de opiniões diversas, desejos ou afeto. E é nesse sentido que a transformação da sociedade pode nortear o comportamento de indivíduos e até mesmo do grupo familiar o qual se insere. Afirmar-se que a vida teria um aspecto passageiro, não implicaria cair em um vazio existencial. Pelo contrário, implicaria em aprender a reconhecer que algo permanece entre o fluxo de acontecimentos e encontros. É o estar diante da vida como sendo um novo começo, olhar a cada instante, o fazer-se de cada instante, na atitude de valorização de todos os fatos e encontros como sendo a possibilidade de abertura ao Outro, que no âmbito familiar traz importantes consequências ${ }^{11}$.

Uma proteção contra o suicídio é ter uma percepção mais otimista da vida, com razões para se continuar vivendo, opondo-se ao sentimento de desesperança. De maneira geral, é o sentimento de "pertencer", no sentido de possuir forte ligação a alguma coisa, seja a uma comunidade, a um grupo religioso ou étnico, a uma família ou a algumas instituições, que protegem o indivíduo do suicídio. Sob essa ótica, há a percepção da estreita ligação do fenômeno do suicídio com sentimentos de solidão e desesperança presente naqueles com ideação e tentativas ${ }^{10}$.

- Valorização da autoestima entre jovens e adolescentes

Conforme dispõe a Organização Mundial de Saúde - OMS, entre os jovens e crianças é importante que a autoestima seja valorizada, pois a autoestima os protege contra problemas mentais e desesperança, fazendo com que consigam lidar com situações difíceis e estressantes de maneira adequada ${ }^{4}$.

Desse modo, com o fito de promover uma autoestima positiva entre crianças e adolescentes, podem ser utilizadas uma variedade de técnicas, como acentuar as experiências de vida positivas, pois irão ajudar as crianças e jovens a ter uma identificação positiva. Experiências passadas positivas aumentam as chances de um futuro mais autoconfiante nos jovens ${ }^{4}$.

Crianças e adolescentes não devem sofrer pressões de maneira constante para fazerem mais ou melhor. Não é suficiente que adultos digam que amam as crianças, já que elas necessitam de sentir-se amadas, pois há uma diferença entre ser amado e sentir-se amado. Crianças não devem ser somente aceitas, mas também, ser desejadas como são. Devem sentir-se especiais simplesmente pelo fato de sua existência. Para o desenvolvimento de uma autoestima positiva no início da infância, é necessária a construção de blocos de autonomia e domínio. Sendo que tal desenvolvimento em crianças e adolescentes depende que alguns aspectos sejam estimulados, como as suas habilidades físicas, sociais e vocacionais ${ }^{4}$.

A busca pela elevada autoestima entre crianças e adolescentes necessita que estes últimos venham a estabelecer uma independência definitiva da família e colegas, com acapacidade de se relacionar com o sexo oposto, preparando-se para uma ocupação que seja capaz de lhes prover o sustento próprio, bem como estabelecer uma filosofia de vida que seja significativa e praticável, promovendo estabilidade e continuidade no processo de estudos ${ }^{4}$.

Por fim, crianças e adolescentes devem ser ensinados a levarem seus próprios sentimentos seriamente e serem encorajados a confiar naqueles que lhe são mais próximos, como os pais e outros adultos, professores, médicos, enfermeiros, amigos, treinadores esportivos e educadores religiosos ${ }^{4}$.

Nesse aspecto, tem-se que a promoção de diálogos é de crucial significado no processo de prevenção ao suicídio, pois na maioria dos casos, 
crianças e adolescentes que estão sofrendo com crises de comportamento suicida também possuem problemas de comunicação. Ressaltando que tal comunicação deve ser estabelecida com confiança entre os pares. A falta de diálogo e uma rede desestruturada, resultam em um silêncio e um aumento das tensões nos relacionamentos; ambivalência óbvia, ou seja, a confrontação de adultos com uma criança ou adolescente suicida traz seus próprios conflitos à tona; agressão direta ou indireta, verbal ou não verbal ${ }^{4}$.

No mais, cumpre pontuar que crianças ou adolescentes em conflitos ou com crise de suicídio são muitas das vezes hipersensíveis ao estilo de comunicação das outras pessoas na maior parte do tempo. Isto se explica porque durante o seu desenvolvimento as mesmas tiveram relacionamentos de pouca confiança com os seus familiares e colegas, além de terem vivenciado uma falta de interesse, respeito ou até amor. Essa hipersensibilidade dos jovens suicidas pode ser perceptível tanto em suas comunicações verbais quanto não verbais comunicações corporais ${ }^{4}$.

Por fim, frise-se que é comum um comportamento ambivalente entre crianças e adolescentes no que diz respeito a aceitar ou não ajuda que lhes é oferecida, e em relação a viver ou morrer. Tal ambivalência tem repercussões evidentes no comportamento dos jovens suicidas, os quais podem apresentar mudanças súbitas, no sentido de procurar e logo depois rejeitar a ajuda, fato que pode acarretar uma má interpretação pelos outros que não tem compreensão do que está ocorrendo ${ }^{4}$.

\section{CONSIDERAÇÕES FINAIS}

Diante do quanto exposto, pode-se concluir que os suicídios são evitáveis. E para tanto, existem várias medidas preventivas que podem ser tomadas em vários níveis, como no populacional, subpopular e individual com a finalidade de evitar suicídio e tentativas de suicídio ${ }^{7}$. Nesse contexto, cumpre pontuar e dar especial atenção para a questão da tentativa de suicídio, pois é o principal fator de risco para uma futura efetivação desse intento 9 .

Além disso, a prevenção também pode ser feita no ambiente escolar, lembrando: "A escola deve ser um espaço que desperte nos estudantes o desejo pela vida e o interesse pelo mundo externo. Além disso, deve estar pronta para acolher os/as jovens que estão no processo de construção de seu projeto de vida"9. Ainda, quando a questão é a prevenção, propõe-se, para tanto, que estratégias de promoção de qualidade de vida, recuperação da saúde e prevenção de danos sejam promovidas pela sociedade, permitindo maior reflexão sobre a importância da família, sobre o uso de novas tecnologias, pela busca pelo sentido da vida e valorização da autoestima em crianças e adolescentes 9 .
Em primeiro lugar, a família, porque seria parte fundamental e integrante de uma rede psicossocial que dá suporte ao indivíduo e pode ser um recurso na prevenção ao suicídio. É a experiência na família que demarca/restringe o sentido da vida ao sujeito $^{11}$. Segundo, o controle do uso de tecnologias, pois deve-se ter em mente que o uso imoderado das mesmas pode ocasionar prejuízos para a saúde do homem, notadamente porque estão associadas a transtornos, como a alienação mental, amnésia digital, ansiedade, despreparo para frustações, compulsão, depressão, déficit de atenção, demência digital, transtornos urbanos, visão comprometida, sono sem qualidade, obesidade, nomofobia, dentre outros prejuízos, como o cyberbullying ${ }^{11}$.

Ademais, tem-se o fato de que a busca pela felicidade muitas vezes está ligada a aquisição contínua de bens e serviços amplamente divulgada pelas redes sociais e meios publicitários. E é esse o ponto de preocupação, pois altos índices de suicídio decorrem da contradição existente entre o modelo de felicidade que é veiculado pelas redes socias através do consumo exacerbado, em contraposição ao fato de que poucos podem consumir, ou mesmo não podem ter acesso ao que veem, ou poucos se contentam com os produtos que consomem ${ }^{11}$. Nesse cenário podemse verificar casos em que prevalece a dependência de objetos de desejo, evitando a mediação a favor de outros objetos, o que faz surgir um comportamento marcado pela impulsividade. Ou, em casos diversos, o indivíduo sente-se desiludido ou até mesmo traído por uma promessa que não foi satisfeita, a de que o consumo atrairia a tão sonhada felicidade ${ }^{11}$.

Um terceiro ponto a ser enfrentado, seria a busca pelo sentido da vida. A morte seria um fato que conduz o indivíduo a dimensões simbólicas e existenciais que ultrapassam questões de tempo e espaço. É um acontecimento irremediável que marca o fim da vida humana, e que, portanto, levanta indagações a despeito de qual seria o sentido de viver, requerendo tentativas de respostas. Tais questionamentos são objeto de investigações humanas há tempos, em diferentes culturas e épocas, produzindo formas culturalmente novas capazes de enfrentar os desafios da sobrevivência humana, como o desenvolvimento da ciência, da arte, literatura e religião ${ }^{11}$.

Por fim, fator fundamental na prevenção ao suicídio, sobretudo entre os jovens e crianças seria a valorização da autoestima, pois a autoestima os protege contra problemas mentais e desesperança, fazendo com que consigam lidar com situações difíceis e estressantes de maneira adequada. Para tanto, podem ser utilizadas algumas técnicas, como a acentuação de experiências de vida positivas, pois irão ajudar as crianças e jovens a ter uma identificação positiva. Experiências passadas positivas aumentam as chances de um futuro mais 
autoconfiante nos jovens. Como também, a construção de blocos de autonomia e domínio através do estímulo de suas habilidades físicas, sociais e vocacionais ${ }^{4}$.

A busca pela elevada autoestima entre crianças e adolescentes necessita que este últimos venham a estabelecer uma independência definitiva da família e colegas, com a capacidade de se relacionar com o sexo oposto, preparando-se para uma ocupação que seja capaz de lhes prover o sustento próprio, bem como estabelecer uma filosofia de vida que seja significativa e praticável, promovendo estabilidade e continuidade no processo de estudos ${ }^{4}$. Portanto, além do disposto, é de suma importância que na prevenção ao comportamento suicida deve-se ter em mente alguns itens essenciais, tais como: não deixar a pessoa sozinha, tirar de perto armas de fogo, álcool, drogas ou objetos cortantes, levar o indivíduo com ideação para assistência especializada e promover apoio emocional de forma presencial ou digital ${ }^{6}$.

\section{REFERENCIAS}

1. Guia Intersetorial de Prevenção do Comportamento Suicida em Crianças E Adolescentes; 2019.

2. Kovacs MJ. Morte e desenvolvimento humano. São Paulo: Casa do Psicólogo; 1992.

3. Rocha GMA. Condutas autolesivas: uma leitura pela Teoria do Apego. Rev Bras Psicologia. 2015;2(01):62-70.

4. OMS. Organização Mundial de Saúde. Prevenção do suicídio um recurso para conselheiros. Departamento de Saúde Mental e de Abuso de Substâncias. Gestão de Perturbações Mentais e de Doenças do Sistema Nervoso. Genebra; 2006.p.9-11.

5. Durkheim E. O Suicídio. estudo de Sociologia. São Paulo: Martins Fontes; 2000.

6. Franco M. Após experiências familiares, psicóloga vira 'suicidologista' para prevenir casos. Folha de S. Paulo, São Paulo, 29 out. 2018. Disponível em: <https://www1.folha.uol.com.br/equilibrioesaude/ 2018/10/apos-experiencias-familiares-psicologavira-suicidologista-para-prevenir-casos.shtml>. Acesso em: 02 fev. 2020.

7. WHO. World Health Organization. Suicide. Geneva; 2019. Disponível em: <https://www.who.int/news-room/factsheets/detail/suicide>. Acesso em: 13 jan. 2020.

8. WHO. World Health Organization. Comprehensive mental health action plan 20132020. Geneva; 2013. Disponível em: <https://www.who.int/mental_health/action_plan_ 2013/en/>. Acesso em: 13 jan. 2020.

9. Botega NJ. Comportamento suicida: epidemiologia. Psicologia USP. 2014;25(3):231-36.
10. Brasil. Ministério da Mulher, da Família e dos Direitos Humanos. O suicídio e a automutilação tratados sob a perspectiva da família e do sentido da vida. 2019. p. 1-42.

11. Moraes, FT. Depressão em adolescentes cresce impulsionada por uso de redes sociais. Folha de S. Paulo, São Paulo, 5 nov. 2018. Disponível em: <https://www1.folha.uol.com.br/equilibrioesaude/ 2018/11/depressao-em- adolescentes-cresceimpulsionada-por-uso-de-redes-sociais.shtml>.

Acesso em: 01 fev. 2020.

12. University of Michigan Health System. Pediatricians update digital media recommendations for kids. ScienceDaily. 2016. Disponível em: https://www.sciencedaily.com/releases/2016/10/1 61021093834.htm>. Acesso em: 20 jan. 2020.

\section{CONFLITO DE INTERESSES}

Os autores declaram não haver conflitos de interesse.

\section{AUTOR PARA CORRESPONDÊNCIA}

\section{Camila Mazza da Silva}

camazzasilva@gmail.com

Submetido em 24/04/2020 Aceito em 06/07/2020 